\title{
Residual lesions in patients who underwent microsurgical clipping of cerebral aneurysms
}

\author{
(iD) Guilherme Brasileiro de Aguiar ${ }^{1}$ \\ (iD) Matheus Kohama Kormanski² \\ (iD) Andrew Vinícius de Souza Batista \\ (D) Mario Luiz Marques Conti ${ }^{4}$ \\ (iD) José Carlos Esteves Veiga
}

\begin{abstract}
1. Mestre, Neurocirurgião/Neurorradiologista Intervencionista e Professor, Faculdade de Ciências Médicas da Santa Casa de São Paulo (FMSCSP), SP, Brasil. 2. Estudante de Medicina. Faculdade de Ciências Médicas da Santa Casa de São Paulo (FMSCSP), SP, Brasil. 3. Residente de Neurocirurgia, FAculdade de Ciências Médicas da Santa Casa de São Paulo (FMSCSP), SP, Brasil. 4. Doutor, Neurocirurgião/Neurorradiologista Intervencionista e Professor, Faculdade de Ciências Médicas da Santa Casa de São Paulo (FMSCSP), SP, Brasil. 5. Doutor, Professor Titular da Disciplina de Neurocirurgia da Faculdade de Ciências Médicas da Santa Casa de São Paulo (FMSCSP), SP, Brasil.
\end{abstract}

http://dx.doi.org/10.1590/1806-9282.66.5.701

SUMMARY

Microsurgical clipping is currently the main method of treating cerebral aneurysms, even with the improvement of endovascular therapy techniques in recent years. Treatment aims at complete occlusion of the lesion, which is not always feasible. Although appearing superior to endovascular treatment, microsurgical clipping may present varying percentages of incomplete occlusion. Such incidence may be reduced with the use of intraoperative vascular study. Some classifications were elaborated in an attempt to standardize the characteristics of residual lesions, but the classification criteria and terminology used in the studies remain vague and poorly documented, and there is no consensus for a uniform classification. Thus, there is also no agrément on which residual aneurysms should be treated. The aim of this study is to review the literature on residual lesions after microsurgery to treat cerebral aneurysms and how to proceed with them.

KEYWORDS: Intracranial aneurysm. Cerebral angiography. Microsurgery. Treatment failure. Reoperation.

\section{INTRODUCTION}

Microsurgical clipping remains the main therapeutic method used in brain aneurysms, despite the advancement in endovascular therapy techniques in recent years'. The aim of the treatment is to promote the complete occlusion of the lesions, thus avoiding future bleeding and preserving the flow of the artery involved. However, it is not always possible to guarantee total occlusion of the aneurysm, so the prevalence of residual lesions may be more than one-third of the cases in some studies. In the literature studied, we observed a great variability of this data, with values ranging from $1.6 \%$ to $42 \%{ }^{1-3}$.
Some factors are related to a higher incidence of residual lesions, such as the size and morphology of the aneurysm, its location and the relationship with the vessel, the number of clips used during the procedure, and the age of the patient ${ }^{1.4}$. In general, the incomplete treatment of aneurysms may be associated with ruptures of these lesions and a consequent increase in morbidity and mortality ${ }^{2}$. The objective of this study is to conduct a review of the literature regarding residual lesions after microsurgery for the treatment of cerebral aneurysms and how to proceed when faced with this finding. 


\section{METHODS}

This is a descriptive study of the literature available in the Medline/PubMed databases. For the search, we used the English terms "intracranial aneurysm”, "microsurgical clipping”, “cerebral angiography”, and "aneurysm remnant". The papers considered relevant were included in this review, as well as the works referenced therein, in order to sensitize the method. Duplicated papers were discarded.

\section{DISCUSSION}

The follow-up of patients with cerebral aneurysmal disease treated by microsurgery or endovascular technique must include, ideally, imaging control to identify the presence and growth of residual lesions as well as the emergence of new aneurysms ${ }^{5-7}$. This care should be provided particularly for young patients, who have greater life expectancy ${ }^{8}$.

The study by Dellaretti et al. ${ }^{4}$, conducted with 90 patients treated by microsurgery, showed a likelihood of bleeding of residual necks of 0.38-0.79\% per year ${ }^{4}$, while the studies by David et al. ${ }^{8}$ and Jabbarli et al. ${ }^{1}$ reported a risk of $1.5 \%$ and $1.9 \%$ per year, respectively. In addition to the risk of bleeding, in the casuistry presented by Brown et al.9, there was an increase in the size of residual lesions in $13.6 \%$ of the cases treated by microsurgery.

Thus, even in cases in which aneurysm clipping is considered complete in the intraoperative period and in the control angiography, long-term monitoring demonstrates there is a risk of lesion recurrence and spontaneous bleeding ${ }^{2,10,11}$. Sindou et al. ${ }^{3}$ highlight the cases of aneurysms considered "giant" or of difficult access, for which the benefits of control examination outweigh the risks inherent to invasive diagnostic procedures. The time required for the follow-up of these patients, however, is still not well defined in the literature $^{1}$ and may be up to ten years.

Residual lesions should be evaluated based on imaging tests that allow for the best morphological characterization. Cerebral arteriography is the method of choice, despite the risks associated with the procedure $^{11-13}$. In addition to confirming the complete occlusion of aneurysms, it is the main exam to assess the presence of residual necks, follow the growth of lesions, detect incorrect positioning of clips, as well as diagnose the presence of new aneurysms ${ }^{14.15}$. Angiotomography and magnetic resonance angiography use noninvasive techniques for evaluating the vascular anatomy of the brain, but are less reliable to detect residual necks than angiography and should not be used alone to rule out lesions in order to avoid false negatives $^{11.12}$.

Due to the morphological variety of aneurysms and formats of clips currently available, residual lesions may have different characteristics. Figure 1 outlines some possible presentations of residual necks due to incomplete clipping of the aneurysm, and Figure 2 shows the arteriographies of the three illustrative cases. Several systems have been developed over the years in an attempt to standardize the characteristics of residual lesions like these, but the classification criteria and the terminology used in different works

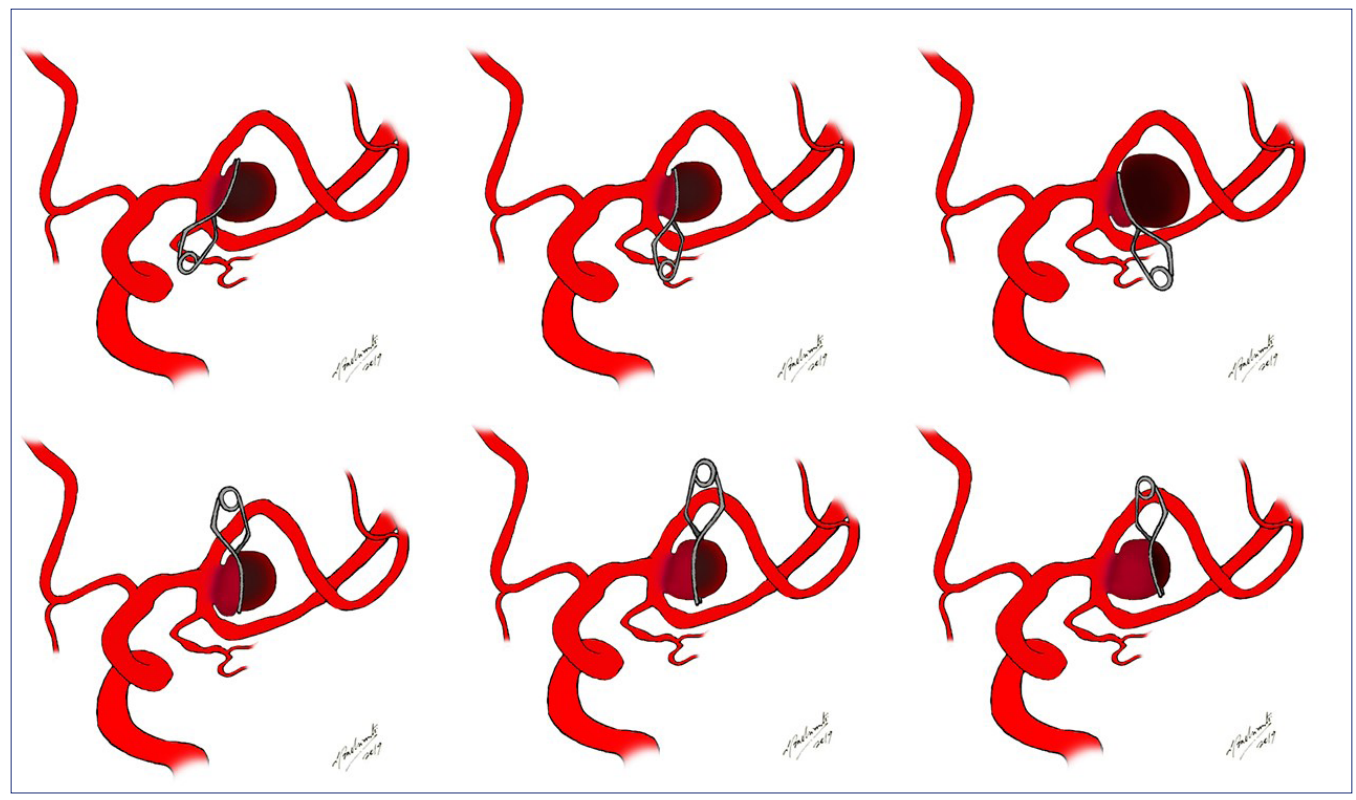

FIGURE 1.

SCHEMATIC

REPRESENTATION

OF BIFURCATION

ANEURYSM OF

THE MIDDLE

CEREBRAL

ARTERY, SHOWING

DIFFERENT

POSSIBILITIES OF

RESIDUAL LESIONS

(ADAPTED FROM

SINDOU ET AL ${ }^{3}$

AND DAVID ET

$\left.A L^{8}\right)$. 
remain vague and poorly documented ${ }^{16}$. The most famous and used system was developed by Sindou et al. $^{3}$, in 1998, and separates the morphology of residual lesions into five categories: I - less than 50\% of the neck of the aneurysm; II - over $50 \%$ of the neck of the aneurysm; III - residual lobe in a multilobed aneurysmal sac; IV - residual sec smaller than $75 \%$; V - residual sac bigger than $75 \%$. The division proposed establishes that lesions classified as I and II benefit less from a new procedure, while lesions III to V should be considered for microsurgical or endovascular retreatment ${ }^{3}$.

Another existing classification, proposed by David et al. ${ }^{8}$, in 1999, divides the residual aneurysms into two possible morphologies. In the dog ear residua variant, which corresponded to 8 of the 12 residual necks obtained in this study, a small residual portion of the aneurysm can be seen between the vessel and the clip, presenting an annual risk of hemorrhage of up to $1.9 \%^{8}$. This would be the variant with a greater risk of in the short term. The other variant is the broad-based residua, in which the aneurysm encompasses a more extensive portion of the circumference of the vessel. Although no bleeding occurred in the lesions classified in the second subgroup, the study considered that the lesions of the broad-based residua type presented higher growth in comparison with the first variant ${ }^{8}$.

More recent systems have been proposed in an attempt to standardize the nomenclature and classification criteria, but none is completely validated or reliable; thus, there is no consensus in the current literature ${ }^{16}$.

In the studies analyzed, the prevalence of reported residual lesions ranged from $1.6 \%$ to $42 \%^{1-3}$, which denotes great heterogeneity among the results. In the study by Sindou et al. ${ }^{3}$, published in 1998, 246 patients were submitted to the surgical clipping of 305 intracranial lesions, resulting in a percentage of 5.9\% residual lesions. A more recent study by Jabbarli et al. ${ }^{1}$ showed a percentage of $18.2 \%$ in the first postoperative control angiography ${ }^{1}$, corresponding to 112 incomplete clippings out of the 616 lesions treated. More recently, the use of intraoperative vascular study using indocyanine green and the routine use of intraoperative subtraction angiography in hybrid operating rooms has contributed to the reduction in cases of incomplete microsurgical treatment of aneurysms ${ }^{17.18}$ and, although results are promising, such techniques are not available in most services.

From the advent of endovascular therapy for brain aneurysms, in the 1990s, the comparison between

\section{FIGURE 2}

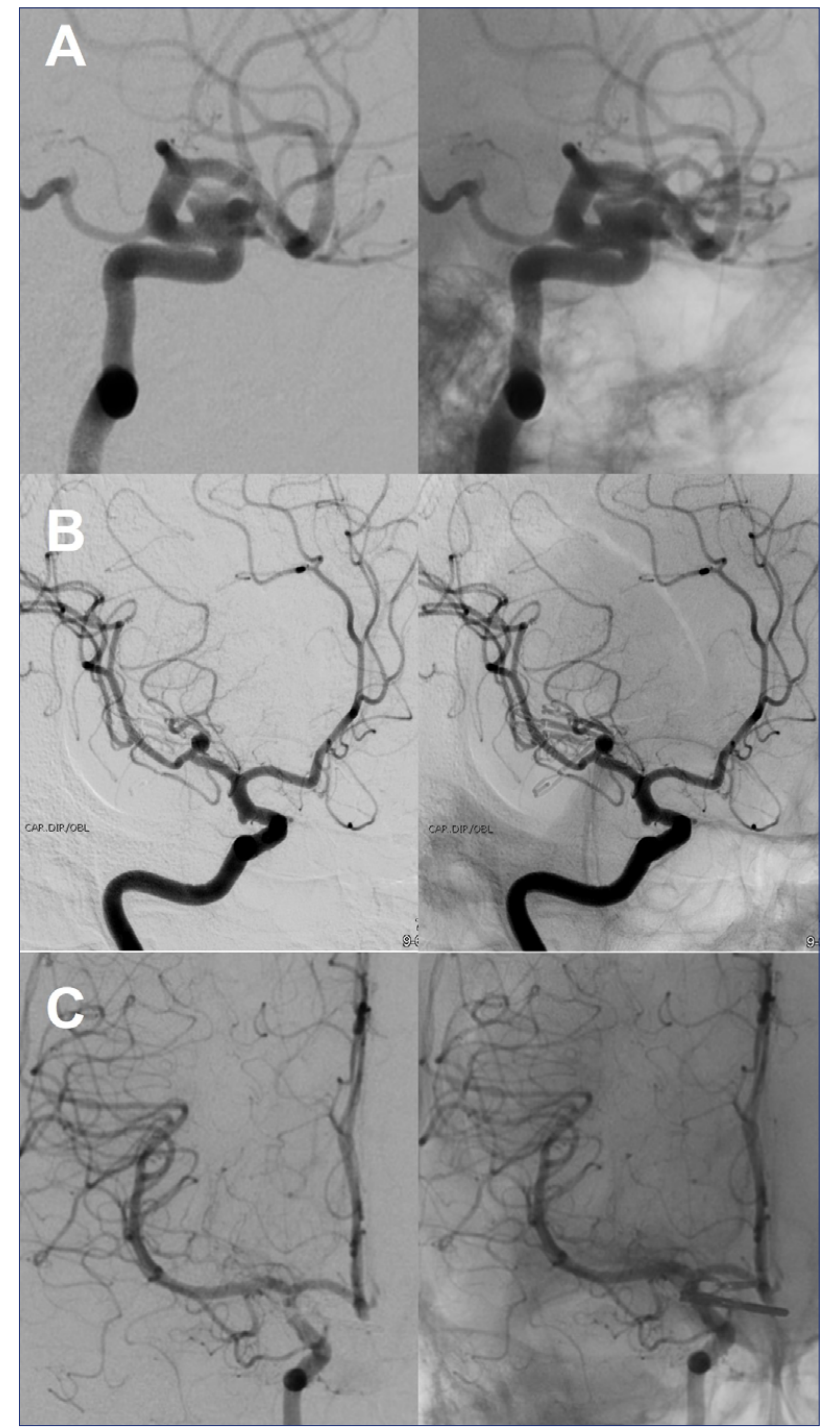

FIGURE 2. ARTERIOGRAPHY OF CAROTID ARTERIES OBTAINED AFTER MICROSURGICAL TREATMENT OF CEREBRAL ANEURYSMS, SHOWING RESIDUAL LESIONS. FIGURE A SHOWS THE INCOMPLETE CLIPPING OF THE OPHTHALMIC SEGMENT ANEURYSM OF THE INTERNAL CAROTID ARTERY; B SHOWS A RESIDUAL ANEURYSM IN THE M1 SEGMENT OF THE MIDDLE CEREBRAL ARTERY; C ILLUSTRATES A RESIDUAL LESION IN AN ANTERIOR INTERCONNECTING ANEURYSM COMPLEX (IMAGES WITH AND WITHOUT DIGITAL SUBTRACTION ARE REPRESENTED IN THE FIRST AND SECOND COLUMNS, RESPECTIVELY).

this new treatment modality and the microsurgical approach, previously established, became frequent ${ }^{1.19}$. One of the main divergent aspects between the techniques is precisely the rate of complete and permanent aneurysm occlusion.

In the ISAT (International Subarachnoid Aneurysm Trial) ${ }^{20}$ study, published in 2005, 2,143 patients with 
ruptured intracranial aneurysms were randomized to receive microsurgical or endovascular treatment. Among the cases submitted to endovascular therapy, follow-up angiographies showed $8 \%$ of residual necks, with $26 \%$ of subtotal occlusion, and $66 \%$ of total occlusion. The angiographies performed in patients post-microsurgical clipping, on the other hand, showed a rate of $6 \%$ of incomplete occlusions, $12 \%$ of subtotal occlusions, and $82 \%$ of complete occlusions.

In 2009, new data derived from the ISAT study were published regarding the long-term follow-up of patients ${ }^{\mathbf{1 4}}$. With an average of nine years of angiography follow-up, the study showed a higher rate of rebleeding in patients submitted to endovascular therapy in comparison to those who underwent the surgical approach, although no statistical difference was found between the groups regarding post-treatment mortality from bleeding ${ }^{14}$. Curiously, the work by $\mathrm{Yu}$ et al. ${ }^{21}$ indicates that the residual aneurysms after microsurgery have a greater tendency of bleeding than after endovascular treatment.

More recently, a meta-analysis published by Li et al. ${ }^{19}$ that used four clinical trials and 23 observational studies on the two modalities of treatment showed greater benefits from microsurgical clipping for the complete occlusion of aneurysms and in reducing the risk of bleeding. Endovascular therapy showed positive results in patients with good preoperative status, but the technique was inferior to microsurgery in the main outcomes evaluated by the study ${ }^{19}$.

The indications for the treatment of residual lesions - either after microsurgery or embolization are still controversial and lack of evidence to justify the risks of a new approach ${ }^{2}$. However, due to the risk of hemorrhage, David's “dog-ear residua” lesions and Sindou's classes IV and V should be evaluated carefully for retreatment aiming at their complete occlusion.
Lesions with less risk of rebleeding must be followed-up by imaging exams.

\section{FINAL CONSIDERATIONS}

The literature regarding the treatment of intracranial aneurysms and the management of residual necks proved to be heterogeneous and inconclusive in several aspects, especially with regard to the monitoring, classification, and approach of residual lesions. Despite these differences, the revision of studies allows us to affirm that vascular studies based on neuroimaging methods are mandatory for follow-up after microsurgery to evaluate the complete occlusion of the lesions and the emergence of new aneurysms. The rates of incomplete occlusion are variable but, in general, low. The treatment is indicated for residual lesions with a higher chance of rupture. For lesions of lower risk, a series of follow-up imaging exams is recommended.

\section{Statement of conflict of interests}

All the authors declare complete and total exemption from any conflict of interest with any commercial product, equipment, or company.

\section{Authors' contributions}

Guilherme Brasileiro de Aguiar: Concept, methodology design, collection of data, drafting of the manuscript; Matheus Kohama Kormanski: Concept, methodology design, collection of data, drafting of the manuscript; Andrew Vinícius de Souza Batista: Concept, methodology design, collection of data, drafting of the manuscript; Mario Luiz Marques Conti: Concept, revision of the text; José Carlos Esteves Veiga: Concept, methodology design, revision of the text.

\section{RESUMO}

A clipagem microcirúrgica é, atualmente, o principal método de tratamento dos aneurismas cerebrais, mesmo com o aprimoramento das técnicas de terapia endovascular nos últimos anos. O tratamento visa à oclusão completa da lesão, o que nem sempre é factível. Apesar de parecer superior ao tratamento endovascular, a clipagem microcirúrgica pode apresentar porcentagens variadas de oclusão incompleta. Tal incidência pode ser reduzida com utilização de estudo vascular intraoperatório. Algumas classificações foram elaboradas na tentativa de padronizar as características das lesões residuais, mas os critérios de classificação e a terminologia utilizados nos trabalhos mantêm-se vagos e pobremente documentados, não havendo consenso para uma classificação uniforme. Dessa forma, não há também concordância sobre quais aneurismas residuais devam ser submetidos a tratamento. O objetivo do presente estudo é realizar uma revisão da literatura a respeito das lesões residuais após microcirurgia para tratamento dos aneurismas cerebrais e como proceder diante dessas. 


\section{REFERENCES}

1. Jabbarli R, Pierscianek D, Wrede K, Dammann P, Schlamann M, Forsting $\mathrm{M}$, et al. Aneurysm remnant after clipping: the risks and consequences. Neurosurg. 2016;125(5):1249-55.

2. Johnston SC, Dowd CF, Higashida RT, Lawton MT, Duckwiler GR, Gress DR. CARAT Investigators. Predictors of rehemorrhage after treatment of ruptured intracranial aneurysms: the Cerebral Aneurysm Rerupture After Treatment (CARAT) study. Stroke. 2008;39(1):120-5.

3. Sindou M, Acevedo /C, Turjman F. Aneurysmal remnants after microsurgical clipping: classification and results from a prospective angiographic study (in a consecutive series of 305 operated intracranial aneurysms). Acta Neurochir (Wien). 1998;140(11):1153-9.

4. Dellaretti M, Silva Martins WC, Dourado JC, Faglioni Junior W, Quadros RS, de Souza Moraes VV, et al. Angiographic and epidemiological characteristics associated with aneurysm remnants after microsurgical clipping. Surg Neurol Int. 2017;8:198

5. Tsutsumi K, Ueki K, Morita A, Usui M, Kirino T. Risk of aneurysm recurrence in patients with clipped cerebral aneurysms: results of long-term follow-up angiography. Stroke. 2001;32(5):1191-4.

6. Akyüz M, Tuncer R, Yilmaz S, Sindel T. Angiographic follow-up after surgical treatment of intracranial aneurysms. Acta Neurochir (Wien). 2004; 146(3):245-50

7. Suzuki MT, Aguiar GB, Jory M, Conti ML, Veiga IC. De novo basilar tip aneurysm. Case report and literature review. Neurocirugia (Astur) 2011;22(3):251-4.

8. David CA, Vishteh AG, Spetzler RF, Lemole M, Lawton MT, Partovi S. Late angiographic follow-up review of surgically treated aneurysms. J Neurosurg. 1999;91(3):396-401.

9. Brown MA, Parish |, Guandique CF, Payner TD, Horner T, Leipzig T, et al. A long-term study of durability and risk factors for aneurysm recurrence after microsurgical clip ligation. | Neurosurg. 2017;126(3):819-24.

10. Thornton ], Bashir Q, Aletich VA, Debrun GM, Ausman II, Charbel FT. What percentage of surgically clipped intracranial aneurysms have residual necks? Neurosurgery. 2000;46(6):1294-8.

11. Uricchio M, Gupta S, Jakowenko N, Levito M, Vu N, Doucette J, et al. Computed tomography angiography versus digital subtraction angiography for postclipping aneurysm obliteration detection. Stroke. 2019;50(2):381-8.
12. Dündar TT, Aralaşmak A, Özdemir H, Seyithanoğlu MH, Uysal Ö, Toprak $\mathrm{H}$, et al. Comparison of TOF MRA, contrast-enhanced MRA and subtracted CTA from CTP in residue evaluation of treated intracranial aneurysms. Turk Neurosurg. 2017. doi: 10.5137/1019-5149.JTN.21113-17.2.

13. Thaker NG, Turner JD, Cobb WS, Hussain I, Janjua N, He W, et al. Computed tomographic angiography versus digital subtraction angiography for the postoperative detection of residual aneurysms: a single-institution series and meta-analysis. J Neurointerv Surg. 2012;4(3):219-25.

14. Molyneux AJ, Kerr RS, Birks J, Ramzi N, Yarnold J, Sneade M, et al; ISAT Collaborators. Risk of recurrent subarachnoid haemorrhage, death, or dependence and standardised mortality ratios after clipping or coiling of an intracranial aneurysm in the International Subarachnoid Aneurysm Trial (ISAT): long-term follow-up. Lancet Neurol. 2009;8(5):427-33.

15. Murphy M, Bell D, Worth RD, Jehle KS, Critchley GR, Norris JS. Angiography postclipping and coiling of cerebral aneurysms. Br | Neurosurg. 2005; 19(3):225-8

16. Kotowski M, Farzin B, Fahed R, Guilbert F, Chagnon M, Darsaut TE, et al. Residual cerebral aneurysms after microsurgical clipping: a new scale, an agreement study, and a systematic review of the literature. World Neurosurg. 2019;121:e302-21.

17. Doss VT, Goyal N, Humphries W, Hoit D, Arthur A, Elijovich L. Comparison of intraoperative indocyanine green angiography and digital subtraction angiography for clipping of intracranial aneurysms. Interv Neurol. 2015;3(3-4):129-34

18. Sharma M, Ambekar S, Ahmed O, Nixon M, Sharma A, Nanda A, et al. The utility and limitations of intraoperative near-infrared indocyanine green videoangiography in aneurysm surgery. World Neurosurg. 2014;82(5):e607-13.

19. Li H, Pan R, Wang H, Rong X, Yin Z, Milgrom DP, et al. Clipping versus coiling for ruptured intracranial aneurysms: a systematic review and meta-analysis. Stroke. 2013;44(1):29-37.

20. Molyneux A|, Kerr RS, Yu LM, Clarke M, Sneade M, Yarnold |A, et al; International Subarachnoid Aneurysm Trial (ISAT) Collaborative Group. International subarachnoid aneurysm trial (ISAT) of neurosurgical clipping versus endovascular coiling in 2143 patients with ruptured intracrania aneurysms: a randomised comparison of effects on survival, dependency, seizures, rebleeding, subgroups, and aneurysm occlusion. Lancet. 2005;366(9488):809-17

21. Yu LB, Fang ZI, Yang XI, Zhang D. Management of residual and recurrent aneurysms after clipping or coiling: clinical characteristics, treatments, and follow-up outcomes. World Neurosurg. 2019;122:e838-46. 